\title{
Hispanismes
}

Revue de la Société des Hispanistes Français

17 | 2021

Murs, barrières, obstacles dans les mondes

hispaniques I

\section{Fronteras, hermetismo y aislamiento forzado en la obra de Carlos Liscano}

Frontières, hermétisme et isolement forcé dans l'œuvre de Carlos Liscano

Borders, hermeticism and forced isolation in Carlos Liscano's corpus

\section{Émilie Leroux}

\section{OpenEdition}

Journals

Edición electrónica

URL: https://journals.openedition.org/hispanismes/13567

DOI: 10.4000/hispanismes. 13567

ISSN: 2270-0765

Editor

Société des Hispanistes Français

\section{Referencia electrónica}

Émilie Leroux, «Fronteras, hermetismo y aislamiento forzado en la obra de Carlos Liscano», Hispanismes [En línea], 17 | 2021, Publicado el 01 junio 2021, consultado el 27 enero 2022. URL: http:// journals.openedition.org/hispanismes/13567 ; DOI: https://doi.org/10.4000/hispanismes.13567

Este documento fue generado automáticamente el 27 enero 2022.

\section{cc) $(1) \odot$}

Les contenus de cette revue sont mis à disposition selon les termes de la Licence Creative Commons Attribution - Pas d'Utilisation Commerciale - Pas de Modification 4.0 International. 


\title{
Fronteras, hermetismo y aislamiento forzado en la obra de Carlos Liscano
}

\author{
Frontières, hermétisme et isolement forcé dans l'œuvre de Carlos Liscano \\ Borders, hermeticism and forced isolation in Carlos Liscano's corpus
}

\section{Émilie Leroux}

\section{Introducción}

1 Memorias de la guerra reciente publicada por primera vez en 1988 y El furgón de los locos, publicada en 2001 por el autor uruguayo Carlos Liscano, presentan ambas una situación de encierro, de aislamiento forzado de un sujeto.

2 La primera, es una obra de ficción en la cual el protagonista es un soldado, alistado de manera forzada, para luchar desde una zona geográfica desconocida en una guerra que nunca aparece realmente en el texto. Su vida, en una zona alejada de las ciudades, en plena naturaleza, y que el lector como el protagonista y sus compañeros desconocen, parece ser un encierro en unas barreras naturales. El protagonista se encuentra en una situación de aislamiento forzado debido a la zona y a las reglas del campo militar.

El furgón de los locos es el testimonio que el autor redactó sobre sus años de encarcelamiento en el Establecimiento de reclusión militar $\mathrm{n}^{\circ}$ 1, conocido como "Penal de Libertad", en Uruguay. Un encarcelamiento que empezó, en 1972, pocos meses antes de la disolución del parlamento uruguayo, acontecimiento que marca el principio de la dictadura cívico-militar uruguaya (1973-1985). El autor fue liberado, junto con los demás prisioneros que poblaban los centros de reclusión uruguayos, en marzo de 1985, luego de la vuelta oficial a la democracia. Este testimonio presenta entonces el aislamiento forzado de los prisioneros y en particular el de Carlos Liscano.

4 A pesar de que se trata de una historia ficticia en Memorias de la guerra reciente y del relato de un pasado reciente y autobiográfico en El furgón de los locos, estas dos obras no 
carecen de similitudes. Notamos que el aislamiento en el que se encuentra el protagonista como el autor-testigo, un aislamiento impuesto por un poder militar, se debe en ambos textos al encierro impuesto a los subalternos (soldado o preso). Un encierro que le impide tener informaciones sobre su propia situación y que se debe a barreras naturales y materiales, como paredes o alambres. Estas barreras y paredes, en nuestra opinión, son fronteras ya que las controlan el poder jerárquico y militar con el fin de vigilar quién puede atravesarlas o no y cuándo. Sin embargo, como las fronteras geográficas y políticas que cada país tiene, sean marcadas materialmente o inducidas por la geografía (fronteras marítimas, montañosas, etc.), el control del poder no impide de manera absoluta el cruce de los que están de un lado u otro de la frontera. Este cruce de la frontera puede ser oficial o clandestino, es decir autorizado por las normas de la institución en la que se encuentra el sujeto o cumplido gracias a fallas que crea el individuo.

5 Las similitudes entre las dos obras de Carlos Liscano ponen en tela de juicio el hermetismo de la frontera, de la distinción, que se suele hacer entre ficción y literatura. Es como si el texto ficticio y testimonio histórico de un pasado reciente encontraran un punto de encuentro que es la expresión de la frontera y que permite la expresión de una memoria o, mejor dicho, de unas memorias del pasado reciente. Así pues, veremos cómo el hermetismo deseado por el poder y manifestado mediante las paredes $\mathrm{y}$ barreras que son fronteras materiales y naturales, actúan en la obra de Carlos Liscano. Cabe estudiar primero el aislamiento como forma de dominación del sujeto aislado, luego las fallas en el hermetismo y los mecanismos que los subalternizados utilizan para pasar clandestinamente las fronteras impuestas. $Y$, finalmente, veremos que la representación de estas fronteras permite al autor recorrer un camino hacia la libertad mediante la escritura y la expresión literaria de la memoria del aislamiento forzado.

\section{Asentar su poder y dominación mediante el aislamiento forzado y el hermetismo}

6 Según el sociólogo Erving Goffman, en su estudio Asiles. Études sur la condition des malades mentaux sobre las instituciones como hospitales psiquiátricos, cárceles, campos de concentración y cuarteles, las barreras rompen la relación interior-exterior del sujeto encerrándolo dentro de las fronteras y limitando o prohibiendo sus contactos con el exterior:

Signe de leur caractère enveloppant ou totalitaire, les barrières qu'elles dressent aux échanges sociaux avec l'extérieur, ainsi qu'aux entrées et aux sorties, et qui sont souvent caractérisées par des obstacles matériels : portes verrouillées, hauts murs, barbelés, falaises, étendues d'eau, forêts ou landes. Ce sont ces établissements que j'appelle "institutions totalitaires".

7 Estos rasgos corresponden a los rasgos de las instituciones de reclusión que Carlos Liscano conoció y que podemos distinguir en su testimonio. Mediante este encierro, el prisionero está aislado del mundo exterior lo que provoca el proceso de asilización descrito por Goffman. La institución da al individuo encarcelado todo lo que necesita para vivir dentro y le impone un funcionamiento preciso.

8 Partiendo de este concepto goffmaniano, Pierre Bourdieu habló de "casernisation» ${ }^{2}$ que traducimos como «cuartelización» y que corresponde al mismo proceso pero vivido por un soldado encerrado en las fronteras del cuartel. Dice: «Le casernisé (la 
"casernisation" est l'équivalent de l'asilisation) est disponible pour tout, toujours, avec le même désenchantement et la même soumission, la révolte faisant elle-même partie d'une forme de soumission à un univers dans lequel tout est possible» ${ }^{3}$. De la misma manera, el soldado aislado se encuentra entre las fronteras de la institución, del cuartel o, en Memorias de la guerra reciente, del campo militar. Y, como el preso, está a disposición de la jerarquía cuyo papel es aplicar el funcionamiento de la institución. Debe cumplir con las decisiones de los militares, aunque éstas sean absurdas como cuando le imponen beber café que en realidad es agua caliente a la que nunca se puede añadir café. Y para no cumplir con esta norma debe pedir una autorización. La jerarquía le quita toda posibilidad de elección libre, le quita su libre albedrío y decide de todo para él. El soldado entonces no dispone de su propio cuerpo. La institución totalitaria tiene un control aparentemente total sobre él, un control posible gracias a la separación, la ausencia de contactos entre él y lo que está del otro lado de la frontera.

9 En los procesos de asilización y de cuartelización, como lo subraya Bourdieu, el individuo asilizado o cuartelizado está a disposición del poder. Para los militares, los subalternos (presos o soldados rasos) están completamente "disponibles". Le mandan hacer un trabajo que no puede negarse a cumplir sin explicaciones y el subalterno no debe cuestionar este trabajo. Es como si fuera un objeto, una mera posesión de los militares. Forma parte del funcionamiento de la institución totalitaria represiva como lo son las cárceles y, en el caso de nuestro estudio, el cuartel en el que el protagonista llega luego de una detención parecida a la detención del propio autor.

10 El objetivo de los militares al aislar forzosamente al individuo en la institución totalitaria es entonces asentar su poder sobre él. Según Michel Foucault, en su estudio Surveiller et punir. Naissance de la prison, se hace convirtiendo el cuerpo del prisionero, o del soldado subalternizado, en "instrumento" en el cual se manifiesta este poder:

Le corps se trouve en position d'instrument ou d'intermédiaire : si on intervient sur lui en l'enfermant, ou en le faisant travailler, c'est pour priver l'individu d'une liberté considérée à la fois comme un droit et un bien. Le corps, selon cette pénalité, est pris dans un système de contrainte et de privation ; d'obligations et d'interdits ${ }^{4}$.

11 De esta manera, como lo explica Foucault, se «garantiza el ejercicio del poder» en el preso o el soldado que depende de la estructura social que ofrece la institución totalitaria. Este poder se expresa directamente en su cuerpo.

Los militares desean entonces ubicar al individuo subalternizado dentro de fronteras completamente herméticas. Sin embargo, el control absoluto de las relaciones de la persona asilizada o cuartelizada es imposible y ésta consigue crear fallas gracias a sus relaciones entre el interior y el exterior de la institución totalitaria. Relaciones que tienen consecuencias tanto dentro como fuera y que se desarrollan alrededor del concepto de ejemplaridad usado por los militares. En ambos textos aparecen ejemplos del funcionamiento y del impacto que tiene la institución en los asilizados y cuartelizados. Son ejemplos que salen de la institución y que se transmiten mediante el cuerpo de los subalternizados. Primero, los prisioneros que un día vuelven a la vida libre, llevan en carne propia el ejemplo del funcionamiento de la institución totalitaria represiva. Asimismo, salen cartas que los prisioneros y los soldados alistados contra su voluntad pueden enviar a sus familiares. Sin embargo, se trata de cartas regidas por las normas de la institución. En Memorias de la guerra reciente leemos:

La carta que estábamos autorizados a escribir no podía sobrepasar los quince renglones, con el tipo de hoja que vendía la Cantina. Debía estar escrita con un bolígra[f]o azul, también de la Cantina; debía estar dirigida a una sola persona cuyo 
nombre completo tenía que aparecer arriba a la izquierda. Esa persona debía ser familiar directo del recluta [...]. La carta debía referirse solo a cuestiones de tipo familiar y personal, no podía dar noticias sobre terceros, tenía que estar escrita en letra legible y tratar sobre "cosas claras". Esto último no era muy definido pero significaba que, en caso de que algo no se entendiera o fuera de mal gusto, la carta sería rechazada sin informar al interesado. Así también estaba claro que las cartas serían leídas antes de ser enviadas, probablemente por el Servicio de Inteligencia, por aquellos miembros del Servicio que, se suponía, estaban integrando nuestras compañías 5 .

13 Las normas así como el "Servicio de Inteligencia" al que se refiere el protagonista son extremadamente parecidos a la censura y a las normas de redacción que conocieron los numerosos presos de la dictadura uruguaya ${ }^{6}$. En ninguno de los dos textos aparecen cartas que recogen el sentido contrario, desde fuera hacia dentro. Las comunicaciones están tan limitadas que al principio de Memorias de la guerra reciente el protagonista cita las palabras de un superior a propósito de la comunicación: «la correspondencia estaba congelada $»^{7}$. Si las cartas manifiestan una salida de la institución, cabe señalar que el control de los militares y la ausencia de respuesta a las cartas enviadas, ubican al preso en una situación de dependencia que corresponde al carácter total de la institución y al proceso de asilización carcelaria: la única referencia del preso es la jerarquía militar, no obtiene informaciones del exterior. De la misma manera, la única fuente de información del soldado, en la obra ficticia, son los superiores; no puede enterarse de elementos sobre su situación por otras personas ya que sus contactos con el exterior son vigilados e imposibilitados.

Así como las cartas, las visitas tienen lugar según el funcionamiento y el reglamento de la institución. En el caso de la obra ficticia, no hay realmente visitas. Sin embargo, la institución es presentada de manera modificada, por ejemplo en el capítulo 18, cuando los reclutas crean jardines luego del anuncio de la llegada de nuevos reclutas, que finalmente no integran la unidad pero notamos el embellecimiento del campo que es anormal y debido a la visita anunciada. En el caso de las visitas que recibían los prisioneros, se supone también una preparación particular y la vigilancia de los militares. Del mismo modo que las cartas, las visitas no pueden permitir al preso asilizado, aislado forzosamente, obtener informaciones que le darían cierto poder frente a los militares. Porque las cartas y las visitas, si no corresponden al hermetismo, tampoco se realizan fuera del control del poder. A propósito de estas visitas, Goffman subraya la especie de hipocresía existente entre las diferentes personas concernidas:

Il est déprimant, humainement parlant, de constater qu'au bout d'un certain temps chacune des trois parties - reclus, visiteur, personnel - a parfaitement pris conscience que le parloir offre une image maquillée de la réalité et que, tout en sachant les autres également conscients de cette situation, tous acceptent tacitement de perpétuer malgré tout la fiction ${ }^{8}$.

Los que visitan a los presos saben entonces muy bien que lo que ven es una representación y que ellos mismos están representándose, como desempeñando una función al esconder elementos a los militares. El lector de la obra liscaniana ve así el funcionamiento de la institución totalitaria que aparece en el texto. Puede notar la ausencia de respuesta que impide un intercambio. La única respuesta es el silencio al que es reducido el correspondiente y que para la persona asilizada o cuartelizada es una respuesta ya conocida en el momento de la escritura de la carta. Simbólicamente, el ser asilizado no puede tener conversaciones y el ser que vive fuera de la institución es indirectamente víctima de la institución por no poder contactar con el familiar 
asilizado de manera libre. Es una asilización que pasa por el aislamiento físico y por el aislamiento social, al contrario de otras instituciones totalitarias, como los hospitales psiquiátricos que pueden autorizar salidas y contactos, la asilización representada es también social. No hay autorizaciones de salidas. El silencio y los temas que están prohibidos en las cartas como durante las visitas vigiladas no carecen de sentido en el período de la escritura y publicación de la obra que corresponde a un momento en que hablar de la dictadura y de lo vivido estaba muy complicado. Así, mediante la obra, el lector asiste a una presentación de la institución e indirectamente de la violencia de Estado.

16 Asimismo podemos notar el impacto social que tiene la institución totalitaria fuera de sus fronteras. El escarmiento es dado de manera evidente a las personas consideradas "subversivas" por el poder antes de su detención. Carlos Liscano escribe: «Es imposible no pensar que en algún momento uno va a ser detenido, y torturado. Es imposible no pensar en cómo hacer para soportar la tortura $»^{10}$. Así pues subraya el miedo a la violencia ejercida en las instituciones de la dictadura y su efecto en las personas que aún no lo han sufrido. El poder advierte con anticipación de las consecuencias de cualquier oposición.

17 Si el preso puede sufrir mentalmente a causa de las paredes de la institución y del funcionamiento de ésta de manera anticipada, es decir antes de su detención por lo que se sabe de la represión carcelaria en el resto de la sociedad; también podemos subrayar que de la misma manera algunos prisioneros volvieron mentalmente al interior de las paredes represivas mediante sus recuerdos. Como un ciclo vicioso en el que estaban los presos a causa del funcionamiento de la institución totalitaria en la que vivieron y del deseo del poder militar de aniquilar su personalidad y toda forma de oposición. Efectivamente, los recuerdos de los presos los podían ubicar de nuevo dentro de las paredes de la institución totalitaria. Fue el caso de Carlos Liscano quien, después de la liberación, mientras estaba en Estocolmo, reconoce la voz de una presa que nunca había visto pero cuyos gritos escuchaba a menudo mientras los militares la torturaban. Cuando la reconoce, le pregunta si es efectivamente ella y así ambos vuelven mentalmente dentro de la institución. Notamos el impacto de la institución en el individuo que tanto la sufrió y que interiorizó mentalmente la frontera de la institución. El recuerdo provoca una autocensura, duda en hacer la pregunta y finalmente la hace en voz baja para no molestar. Es como si el encontrar a una persona que forma parte del grupo de los prisioneros, de los que padecieron la asilización, aniquilara la frontera temporal entre el momento pasado y el momento presente. Ambos se encuentran de nuevo entre las paredes de la institución que ya no son físicas sino psicológicas e interiorizadas por el autor. Liscano dudó en hacer la pregunta a esta mujer precisamente porque se trataba de un recuerdo triste del que se acordaba en un momento alegre. Así pues el espacio de la institución totalitaria, las fronteras de tal lugar siguen teniendo efectos en el tiempo en el individuo que estuvo encerrado.

El miedo está relacionado con el hermetismo de la institución que sirve de arma a los militares que parecen, a primera vista, manejarlo según sus deseos e intereses. En efecto, la institución totalitaria impone el aislamiento hermético a los prisioneros pero los militares pueden actuar dentro de la institución según las informaciones que logran obtener fuera. Carlos Liscano explica en su testimonio que los militares consiguieron encontrar un hospital clandestino en el cual estuvo curado luego de haber sufrido un tiroteo. Escribe: «Ahora han encontrado el hospital donde estuve internado, tienen el 
bastón que yo usé, hecho con un palo de escoba» ${ }^{11}$. Esta nueva información tiene repercusiones dentro de la institución totalitaria ya que buscan las cicatrices de sus heridas y que lo pueden castigar por este acontecimiento anterior a su detención. Del mismo modo, los militares utilizan el hermetismo para obtener aún más informaciones jugando con los tipos de fronteras como las paredes en las cuales encierran a los prisioneros cuando utilizan «espejos unidireccionales»:

Llegamos a un sitio en el que nunca había estado. Es la sala de los espejos. Una sala muy larga, de un lado la pared es un espejo. Se hace pasear a los presos por allí, y del otro lado están ¿quiénes? policías, probablemente colaboradores de la policía, informantes, choferes de taxis, mozos de bares, dueños de quioscos, de hoteles, de pensiones ${ }^{12}$.

19 Entonces mediante las paredes y la maleabilidad del hermetismo que imponen a los presos, los militares intentan obtener nuevas informaciones sobre dichos hombres para asentar aún más su poder. El objetivo buscado mediante «la sala de los espejos» es similar al efecto buscado por el funcionamiento panóptico ${ }^{13}$ que describe Michel Foucault en su estudio sobre la cárcel: ver sin ser visto. Quieren saber, conocer todas las informaciones que podrían resultar importantes en la lucha contra los subversivos que están fuera pero también en la lucha que se desarrolla dentro y gracias a la institución totalitaria. En Memorias de la guerra reciente, la vigilancia del protagonista también aparece cuando es castigado por haber opinado sobre la guerra de la que hablan y en la que teóricamente están luchando: «Le dije también por qué no nos rendíamos, que desde mi punto de vista no me parecía mala idea rendirse. [...] dependía del coronel que era quien me había impuesto la sanción $»^{14}$. El control forma parte del funcionamiento de la institución permitiendo a la jerarquía analizar el comportamiento del individuo encerrado para definir cuál será el «tratamiento», aquí el castigo, para cumplir con el objetivo de la institución.

Podemos notar también que, a pesar de ser un arma de los militares, el hermetismo a veces puede servir la causa de los subalternizados ya que les permite participar en la lucha exterior conservando las informaciones que conocen, lo más posible. Sobre este tema, Carlos Liscano escribe:

El torturador no las tiene todas consigo. Pese a que repita a los gritos "Nosotros tenemos todo el tiempo del mundo para sacarte la información", el prisionero sabe que eso no es verdad. A medida que el preso resiste, y pasa el tiempo, la información que tiene pierde actualidad, deja de ser útil. Quizá los datos que esta noche el preso puede dar, y que permitirán detener a otros, ya no servirán al amanecer ${ }^{15}$.

21 Así pues, el hermetismo no es infalible. Los militares quieren controlar la integralidad de la vida del preso, hasta convertirse en seres dominantes y todopoderosos, en los amos del tiempo. Lo que se debe al totalitarismo y al deseo de este tipo de poder de controlarlo todo, hasta los pensamientos de los individuos, imponiendo su ideología.

\section{La permeabilidad de la institución: fallas en el hermetismo.}

A veces, la cuartelización parece total. En la obra ficticia, el secreto relacionado con el cruce de un lado a otro de la frontera natural se manifiesta con un soldado que es enviado a la Capital para dar un curso. Los demás esperan su regreso, pero cuando por fin vuelve, es enviado a un lugar del campamento al que los demás soldados no van, al 
«Comando de la Unidad» $»^{16}$. El recluta que tiene tal vez conocimientos sobre la situación, que podrían alterar el hermetismo, desaparece y así se preserva la cuartelización. Entonces lo alejan pero podemos pensar que si lo alejan es porque obtuvo informaciones que no hubiera debido conocer y, así, lo separan de los demás. Vemos que presentaba un riesgo, seguramente creó una falla en el hermetismo gracias a sus contactos con las personas a quienes dio clase o que encontró fuera de la institución.

Así pues, a pesar del intento de los militares de ubicar a los subalternos en situaciones de aislamiento forzado total dentro de una institución hermética, aparecen fallas. Consisten en elementos que los militares no pueden controlar o sólo parcialmente. Como lo vimos, el hermetismo impuesto por el poder, arma de los militares, también puede servir a los presos. El control de los contactos entre el subalternizado y el exterior, a pesar del deseo de los miliares, presenta fallas difícilmente controlables. En efecto, si las cartas y visitas están regidas por normas y controladas por un servicio dedicado a la censura, no se puede evitar que los presos intercambien informaciones con sus familiares de manera escondida. Existe el doble lenguaje así como el lenguaje no verbal que permiten a una persona que conoce el contexto, y/o la persona que habla o escribe, entender el mensaje escondido.

Las salidas son casi imposibles para el sujeto aislado dentro de la institución totalitaria en los dos textos que analizamos, por eso son tan importantes. Las salidas más evidentes, luego de las liberaciones, son las fugas de prisioneros. Estas fugas marcan la presencia de una falla material en la institución y en la vigilancia de los militares que participa del hermetismo. Liscano se refiere por ejemplo al Cholo González que fue su compañero de celda: «[...] el Cholo González, cañero. El Cholo estuvo preso, se fugó de la cárcel de Punta Carretas en 1971. En 1972 se refugió en Chile. Viajó después a Cuba. En 1975 salió de Cuba, vía Moscú, Buenos Aires. Su meta era Montevideo» ${ }^{17}$. Este preso pasó tanto las fronteras internacionales que separan los países, como las fronteras de la institución totalitaria en la que se encontraba en el momento de su fuga.

También existe otro tipo de salidas, aún más difícil de controlar: el descentramiento del sujeto. Es decir que el preso o el soldado, en los dos textos sujetos aislados, salen mentalmente del lugar de encierro en el que están. El narrador-protagonista de Memorias de la guerra reciente describe este descentramiento con la expresión estar «fondeado» y explica:

Me sentaba en el escritorio y miraba la tela que tenía delante y que dividía mi oficina de la entrada, y allí me perdía, cavilando lejos, organizando de nuevo mi vida, encontrando nuevos principios, otros fundamentos para seguir existiendo. Ordenaba mis recuerdos y repasaba todo lo que había hecho en la vida, todo lo que hubiera sido posible, lo que no debió ser posible ${ }^{18}$.

Tanto la expresión «cavilando lejos» para expresar la reflexión, el pensamiento con este adjetivo de lugar que parece expresar una salida del locutor, como el término «fondeado» que significa volver al principio de algo «examinando con cuidado» ${ }^{19}$ indican este descentramiento y la subversión del preso frente al orden establecido. El personaje se hace preguntas sobre lo que hubiera hecho diferentemente, lo que no corresponde al objetivo de la cuartelización, al contrario. El cuartelizado debe cumplir sin cuestionar, es la disposición total a la que se refiere Pierre Bourdieu. Entonces, es una falla en el control que quieren ejercer los militares y que permite al sujeto cuartelizado, negar el orden militar y salir mentalmente del encierro como lo subrayan los términos «seguir existiendo». 
Carlos Liscano también vive este momento de descentramiento que describió en su personaje ficticio. Se deja llevar por el pensamiento y podemos citar en particular los recuerdos que evoca luego de la muerte de sus padres. Por ejemplo, a propósito de su madre, describe un recuerdo que en realidad no vivió él mismo, un recuerdo de la infancia de su madre que ella le contó. El yo, el sujeto Carlos Liscano, no aparece en este recuerdo y mentalmente rechaza la situación de la institución. Se centra en el espacio y el tiempo del recuerdo que además corresponden a una imagen de libertad con su madre que está «corriendo descalza por el campo, bajo la lluvia» ${ }^{20}$. Este recuerdo participa del descentramiento. Igualmente, en su testimonio, describe un momento durante su detención en que se deja llevar por el pensamiento y leemos: «Intento seguir fantaseando, irme, volar, no ser yo aunque sea por un rato, creer que todo es suave, agradable, que estoy en mi casa, en una casa, sentado en medio de libros, estudiando, escribiendo $»^{21}$. Podemos notar que el descentramiento lo ubica en su casa, lugar cerrado pero agradable. Asimismo, toma distancia respecto a su ser, lo que aparece en una reflexión más general que concierne a los prisioneros, en la que subraya la necesidad de este descentramiento psicológico para luchar contra el aislamiento forzado, así como una oposición a la institución totalitaria y su funcionamiento. Así, el preso se niega a aceptar la situación y el control total por parte de los militares. Preserva su dominio sobre sus propios sueños y pensamientos que se convierten en refugio al que los militares no pueden acceder. Si la institución se presenta como totalmente hermética, notamos su fracaso debido a la permeabilidad creada mentalmente por el individuo aislado y contra la que los militares no pueden actuar. El descentramiento siendo mental e íntimo, no puede entrar en el funcionamiento de la institución al contrario de la revuelta que forma parte, como lo explicaron Goffman y Bourdieu, del proceso de asilización y que implica una reacción de los miembros de la institución. El descentramiento, como las fugas de presos, es una verdadera subversión por parte del individuo asilizado o cuartelizado.

28 Así pues, los subalternos aislados forzosamente en la institución totalitaria logran pasar la frontera de manera «clandestina», sea física o mentalmente, y marcar así su subversión, su negación del orden y del funcionamiento de la institución.

\section{Un camino hacia la libertad}

La idea del cruce clandestino de la frontera no se limita a las fugas y al descentramiento. Asimismo aparecen en el texto los transportes de los subalternos hacia lugares exteriores a la institución. Carlos Liscano explica haber viajado varias veces en la parte trasera de un camión que lo conducía a Montevideo: «Muchas veces viajé desde el Penal hacia Montevideo en estos años. Nunca vi el paisaje, siempre encerrado en un camión $»^{22}$. Y, del mismo modo, el protagonista de la obra ficticia viaja misionado por su jerarquía hacia un cuartel, en la parte trasera del camión. Esta situación le impide ver el exterior y es como si pasara clandestinamente la frontera natural del campo militar. Sin embargo, cuando está en el cuartel antes mencionado, situado en la capital del país, ni intenta salir ni contacta con su esposa que vive en esta ciudad. Entonces el cuartel y el camión en el que viajó son como extensiones de las fronteras de la institución totalitaria. El narrador-protagonista explica que dudó en escribir a su mujer pero no lo hizo: «La carta de los 31 de diciembre era segura, regular. Cualquier otra comunicación resultaba anormal ${ }^{23}$, notamos el miedo a desobedecer y 
entonces el éxito de la cuartelización que provoca la autocensura. El no seguir el funcionamiento regular del campo militar provoca cierto miedo. Notamos, pues, que la cuartelización funcionó particularmente bien en él, no se rebela contra las reglas que finalmente parece haber aprendido e interiorizado.

El miedo que padece el subalternizado sigue presente en los momentos que preceden su liberación o vuelta a la vida civil. El subalternizado, prisionero como soldado, ya no sabe cómo actuar fuera de las normas y fronteras de la institución. Erving Goffman explica:

Nous avons affaire à un processus plus limité que celui de l'acculturation ou de l'assimilation. Si certains changements culturels se produisent néanmoins, c'est plutôt par la suppression de la possibilité d'actualiser certains comportements, et l'ignorance totale des modifications récemment intervenues dans le milieu extérieur. Ainsi, si le séjour du reclus se prolonge, il peut se produire ce que l'on a appelé une «deculturation» (disculturation) au sens d'une «désadaptation » qui rend l'intéressé temporairement incapable de faire face à certaines situations de la vie quotidienne, s'il doit à nouveau les affronter ${ }^{24}$.

En el momento de salir de la institución totalitaria, el sujeto tiene dificultades para volver a actuar de manera autónoma y libre. Necesita un tiempo de adaptación. Liscano cuenta sus inquietudes:

Si me bajaran en cualquier lugar de la ciudad no sabría qué hacer. [...] Me da un poco de temor. Quiero llegar a un sitio conocido, entre gente conocida.

Hasta ayer me consideraba un individuo fuerte, física y mentalmente fuerte. Ahora me siento débil. No sé qué voy a hacer en la sociedad. [...] No es estimulante, es inquietante, un desafío.

En la cárcel era más cómodo: esto no se puede y lo otro tampoco, y apenas hay algo que se puede. Si la comida llega en hora, se come en hora. Si llega tarde, se come tarde. Y si no llega ni en hora ni tarde, no se come. Esa es la libertad que queda, y no es poca.

Otros deciden todo sobre mí. Yo decido que no me importa lo que decidan. Para el preso vivir es resistir un día, una noche más. Para el ciudadano libre, ¿qué es, cómo vivir? [...] Todos los caminos, la infinitud de la vida está delante de mí. Pero eso me paraliza. ¿Qué camino elijo? 25

Notamos las preguntas que se hace y las diversas expresiones del miedo como «me paraliza», «es inquietante», «Me da un poco de temor», «me siento débil», frente a la necesidad de decidir por sí mismo, de enfrentarse al mundo exterior. Un miedo creado por los militares mediante el funcionamiento del ejército y de la cárcel. Se trata de un miedo que sigue sintiendo a veces, a pesar de su liberación efectiva, y que se manifiesta a través de pesadillas: «Después de vivir quince años en libertad todavía, cada vez menos, vuelve la pesadilla. Estoy en mi casa y vienen a detenerme. [...] Nunca, nunca jamás volverán a llevarme preso $»^{26}$. Es como si la libertad total y absoluta no existiera, el impacto de las fronteras de la institución siendo demasiado fuerte. En su obra ficticia, publicada en 1988, o sea tres años después de su liberación y de la vuelta oficial a la democracia, el protagonista estuvo tan marcado, tan transformado por las fronteras que no logra volver a la vida civil y decide alistarse de nuevo, esta vez voluntariamente, en el ejército de su país: «Apliqué el único método que conocía, el militar. Fijé un objetivo y tracé las líneas para alcanzarlo. [...] Once compañeros, once antiguos camaradas habían vuelto antes que yo, por minutos $»^{27}$. El aislamiento forzado dentro de un lugar cerrado por fronteras naturales marca entonces al individuo en su manera de ver el mundo, la cuartelización fue totalmente eficiente. La institución totalitaria llevó los subalternizados a interiorizar su funcionamiento como si fuera la normalidad y no 
la excepción. Pensamos que la cuartelización interiorizada es un hecho literario que se debe al tiempo que fue necesario al autor para reapropiarse de su cuerpo y liberarse de la memoria del funcionamiento de la institución, del hermetismo en el que vivió durante trece años. Escribir una ficción en la que el protagonista conocía una situación similar de aislamiento forzado y de asilización, pudo permitirle sanar sus propias heridas mediante la literatura.

La cuartelización y la asilización consiguieron transformar conceptos fundamentales, en los subalternos que las padecieron. Se nota un replanteamiento del concepto de "libertad". Una transformación que, tal vez, se debe a la paradoja que representa el estar encerrado en un penal llamado "Libertad"; aunque es por su localización cercana a la ciudad del mismo nombre. Es paradójico porque pone en tela de juicio la concepción intelectual relacionada a la palabra libertad. Notamos este replanteamiento cuando Liscano escribe "años después, cuando yo ya sea un individuo libre que sigue buscando la libertad $\aleph^{28}$, lo que subraya que a pesar de haber salido de la institución totalitaria, no se siente libre por completo. Al final de su testimonio, da su definición de la libertad diciendo «es correr por una inmensa llanura blanca» ${ }^{29}$. Un concepto librado de cualquier obstáculo. Este replanteamiento aparece igualmente en la obra ficticia, publicada por primera vez en 1988. Podemos leer: «Nuestro concepto de la libertad, si es que alguno teníamos antes, había sufrido un cambio radical. La libertad era cumplir sin esperar recompensas extraordinarias, obedecer $»^{30}$. Este cambio, provocado por la vida dentro de las fronteras, la cuartelización, se nota también en la elección del personaje de volver al aislamiento.

A través de las dos obras, notamos que la situación hermética, aunque no fue total gracias a las fallas que consiguieron crear los subalternizados, provocó cambios en el individuo, en su personalidad. El protagonista de Memorias de la guerra reciente, además de volver al campo militar, se interesa en la naturaleza. Interés que nació en sus noches de guardia en plena naturaleza. A esto se añade su compromiso militar y el hecho de que solo pueda vivir siguiendo el funcionamiento del cuartel. La cuartelización parece haber cumplido su objetivo. Las barreras influyeron en el ser hasta cambiar su esencia. Se nota también en el testimonio del autor que empieza hablando de su infancia describiéndose como un niño que lo cuenta todo. Pero el hermetismo que padeció dio a luz a su vocación literaria y pasó a ser un hombre de letras. Sintió la necesidad de este cambio mientras estaba encarcelado y empezó a escribir entre las paredes del Penal de Libertad.

El autor parece ofrecer una respuesta, conscientemente o no, al hermetismo y al aislamiento forzado a través de sus dos obras. El estudio minucioso de los títulos y de los contextos de publicación de las dos obras es muy significativo. Como ya lo dijimos, Memorias de la guerra reciente fue publicada en 1988, tres años después de la liberación de su autor y en un período en que la nación debía asumir las consecuencias del régimen autoritario. Dentro del país estaban los que sobrevivieron, los prisioneros que tuvieron que aprender a vivir a pesar de la desaparición de otros y que estuvieron liberados -amnistiados o, en el caso de 63 presos condenados por crímenes «de sangre», liberados mediante un proceso que consistía en contar cada día pasado en la cárcel para cada preso y multiplicarlo por tres para considerar que el preso había cumplido su condena-; estaban también los militares que habían promulgado leyes de amnistía para que no hubiera posibilidad de castigarlos por los crímenes cometidos durante la dictadura; y el resto de la población que contaba tanto los exiliados que entonces 
pudieron volver como los que o no habían pertenecido a ningún bando o no habían actuado directamente. En este momento, estaba particularmente complicado, para los presos, hablar de lo ocurrido. Se trata de un período de silencio. La obra ficticia de Carlos Liscano, como lo mostramos a lo largo de este artículo, presenta a un protagonista que vive una situación de aislamiento forzado parecida a la que conoció el autor. Así pues, podemos considerar que fue una manera para el autor de hablar, de contar lo ocurrido. Una hipótesis que parece confirmar el título Memorias de la guerra reciente. A pesar de la ausencia de nombre para designar el país del protagonista, el país enemigo o la "Capital $»^{31}$, en el momento de la publicación, en el imaginario uruguayo la guerra reciente era evidentemente la guerra que acababan de vivir, la dictadura cívicomilitar y la violencia armada que implicaba. Cabe entonces centrarse en la concordancia plural de la palabra «Memorias», palabra clave en este período. En la obra ni el protagonista, ni los personajes tienen nombres y apellidos como si no tuvieran personalidad propia, podemos pensar en un efecto de la asilización y cuartelización. Señalamos la existencia de números de identificación que los militares daban a los prisioneros cuando entraban en la institución y con los que los llamaban y designaban. Podemos notar la presencia de dos excepciones en el texto: la tortuga del protagonista (Elsa) y el médico del campo que se llama Carlos, como el autor, y le ofrece la solución al malestar que siente luego de su viaje -«Según él, la terapia posible debía practicarla yo mismo» ${ }^{32}$. $-y$ así, el médico Carlos le explica que la solución está en él, como el autor que sana sus heridas él mismo mediante la escritura. Este término plural "memorias", también puede servir para anunciar el relato de las memorias de los que conocieron situaciones de aislamiento forzado como el autor, como si hablara en nombre de los prisioneros. Frente al silencio, la ficción. Esta obra entonces marcó el principio de un camino literario que permitió al autor liberarse poco a poco del efecto de la asilización, contando una cuartelización lograda ya que el protagonista no desafía sus normas y hasta decide volver a similar situación. Un camino que siguió tres años después con $\mathrm{El}$ furgón de los locos, obra testimonial en la que describe su asilización pero en una reflexión más general sobre los presos de la dictadura. En este título también aparece un plural, «los locos», que designa a los prisioneros que están en el furgón que los conduce hasta sus casas en el momento de liberarlos. Notamos la correspondencia entre los dos títulos que traducen la expresión de la memoria de un grupo y hasta podemos cuestionarlos y preguntarnos si, finalmente, el camino literario que recorre el autor hacia la libertad a través de la escritura de estas dos obras llevaría a hablar de las «Memorias de los locos» y del «Furgón de la guerra reciente», furgón de la liberación y memorias de los que vivieron la dictadura y salieron a veces enloquecidos por la asilización que padecieron. Así pues, estos dos textos presentan características del testimonio que tiene como función la reconstrucción de la identidad del sujeto, como lo sugirieron Michael Pollak y Nathalie Heinich:

[...] tout témoignage sur cette expérience met en jeu non seulement la mémoire, mais aussi une réflexion sur soi. C'est pourquoi les témoignages doivent être considérés comme de véritables instruments de reconstruction de l'identité, et pas seulement comme des récits factuels, limités à une fonction informative ${ }^{33}$.

El autor recorrió este camino literario representando a la vez un pasado de asilizado y una situación similar mediante la ficción pero esta situación tiene un carácter testimonial. Es como una anticipación al testimonio que publicó luego. Le permitió quizás acercarse a la libertad total, liberarse de la asilización, de las fronteras de la 
institución que, como lo vimos, tienen efectos hasta mucho después de la liberación física.

\section{Conclusión}

37 A modo de conclusión podemos decir que a través de su escritura Carlos Liscano recorrió un camino en dirección de la libertad total que estaba obstaculizado por los efectos duraderos de la asilización que conoció a lo largo de sus trece años de detención. Fueron años tanto de aislamiento forzado como de violencia y de tortura, en particular en los primeros meses de su cautiverio en los centros de represión de la dictadura uruguaya. Si pudo liberarse poco a poco de las paredes, de las barreras y pasar los obstáculos que le impedían sentirse realmente libre, fue gracias a las fallas existentes en el hermetismo de la institución que se presenta como total pero que en realidad no lo es. Las fallas que crean los prisioneros durante su detención les permiten tanto negar el orden impuesto por los militares sin padecer sistemáticamente las represalias de sus actos, como crearse un refugio mental para soportar la situación. Situación de asilización que también representa en su obra ficticia ya a tres años de su liberación como una anticipación de su futuro testimonio que le permitirá pasar no página sino frontera.

Al publicar en 1988, Carlos Liscano toma la palabra a través de una obra de ficción pero tanto el título que evoca acontecimientos históricos recientes como el tema, el personaje y la ausencia de indicaciones precisas nos llevan a pensar que fue una manera de expresar la memoria del terrorismo y de la violencia de Estado en Uruguay. Expresar esta memoria del conflicto de manera ficticia da a ver el contexto de escritura y publicación que corresponde a un momento de silencio en la sociedad y de cuestionamientos políticos sobre la amnistía dada a los militares responsables de la dictadura. Precisamente en el momento de la publicación se puso en tela de juicio la llamada "Ley de Caducidad" que impedía demandar a los militares que durante la dictadura actuaron bajo las órdenes de sus superiores. Entonces la ficción permite de alguna manera participar en el debate y abordar los temas de actualidad tanto políticos como sociales. El relato ficticio ofrece una reflexión que finalmente el autor desarrolló en su testimonio después. Una reflexión sobre los militares, la asilización y sus efectos en las personas que la viven.

La ficción entonces le permitió al autor tomar la palabra por primera vez para empezar su propia liberación gracias a la literatura. Podemos pensar que la ficción alimentó la reflexión sobre el tema de la violencia sufrida tanto para el autor como en la sociedad uruguaya de los años posteriores al final de la dictadura. Así, Carlos Liscano pudo tomar la palabra de nuevo, con un testimonio cuando él como la sociedad estaban listos para hablar y recibir el testimonio sobre este pasado reciente y doloroso. 


\section{BIBLIOGRAFÍA}

Alfredo ALZUGARAT, Trincheras de papel. Dictadura y literatura carcelaria en Uruguay, Montevideo, Trilce, 2007.

Hannah ARENDT, Les origines du totalitarisme, Paris, Gallimard, 2002.

John BEVERLEY, Subalternidad y representación, Madrid, Iberoamericana, 2004.

Pierre BOURDIEU, Sociologie générale. Cours au collège de France 1983-1986, Paris, Seuil, 2016, vol. 2.

Catherine COQUIO, «La "vérité" du témoin comme schisme littéraire», Dominique Moncond'huy et Daniel Dobbels (dir.), Les camps et la littérature, Rennes, Presses Universitaires de Rennes, 2006, p. 65-91.

Catherine COQUIO, «L'émergence d'une "littérature" de non-écrivain : les témoignages de catastrophes historiques», Revue d'histoire littéraire de la France, vol. 103, n² 2, 2003, p. 343-363.

Michel foucAuLt, Surveiller et punir. Naissance de la prison, Paris, Gallimard, 1975.

Erving GOFFMAN, Asiles. Études sur la condition sociale des malades mentaux, Paris, Les éditions de minuit, 1968.

Carlos LISCANo, Memorias de la guerra reciente, Montevideo, Trilce, 1993.

Carlos LISCANo, El furgón de los locos, Montevideo, Planeta, 2007.

MOVIMIENTO DE LIBERACIÓN NACIONAL, Tres evasiones de Tupamaros: operaciones Estrella, Abuso, Gallo, Buenos Aires, Baires, 1973.

Thomas PLATT, «Emplois descriptifs et polémiques du concept de violence», Revue internationale de sciences sociales, $\mathrm{n}^{\circ} 132$ (mai 1992), p. 185-191.

Michael POLLAK y Nathalie HEINICH, «Le témoignage», Actes de la recherche en sciences sociales, $\mathrm{n}^{\circ} 62 / 63$ (juin 1986), p. 3-29.

REAL ACADEMIA ESPAÑola, Diccionario de la lengua española, “fondear" [on-line], España, RAE

[disponible el 13/03/2021].

Paul RICœUR, Temps et récits, Paris, Seuil, 1991, t. 1.

Paul RIC๕UR, Temps et récits, t. 3, Paris, Seuil, 1991, t. 3.

Ramiro Esteban zó, «La violencia dictatorial latinoamericana desde la mirada de Carlos Liscano», Cuaderno de Letras, $\mathrm{n}^{\circ} 26$ (enero-junio 2016), p. 179-200.

\section{NOTAS}

1. Erving GoffMAN, Asiles. Études sur la condition sociale des malades mentaux, Paris, Les éditions de minuit, 1968, p. 46.

2. Pierre BOURDIEU, Sociologie générale. Cours au collège de France 1983-1986, Paris, Seuil, 2016, vol. 2, p. 303-304.

3. Id.

4. Michel foucAult, Surveiller et punir. Naissance de la prison, Paris, Gallimard, 1975, p. 18.

5. Carlos Liscano, Memorias de la guerra reciente, Montevideo, Trilce, 1993, p. 28. 
6. Sobre este tema, ver PHILLIPPS-TREBY y TISCORNIA Vivir en libertad, Alfredo Alzugarat, Trincheras de papel: «Los reclusos podrán escribir 1 carta semanal de 2 carillas en hojas separadas de tamaño máximo de 22 x $28 \mathrm{cms}$. c/u con no más de 40 renglones por carilla. La carta deberá estar firmada por el recluso y al dorso de cada hoja deberá lucir el remitente con los datos completos (al igual que en el sobre). Deberán estar escritas en un solo color, en idioma español y no podrán contener subrayados, entrecomillados, poesías ni palabras vulgares u obscenas. No se podrán hacer juicios o valoraciones sobre la política interna y personal del Establecimiento o política nacional e internacional. (Normas disciplinarias a cumplir por los reclusos. Div. Reclusión, Sección Celdario, 100800, mayo de 1976.)»

7. Carlos liscano, Memorias de la guerra reciente, op. cit., 1993, p. 14.

8. Erving GOFFMAN, Asiles. Études sur la condition sociale des malades mentaux, op. cit., p. 153.

9. Término empleado por los representantes de la dictadura cívico-militar para designar a los opositores al régimen, presentados como peligrosos por el poder militar.

10. Carlos LISCANo, El furgón de los locos, Montevideo, Planeta, 2007, p. 61.

11. Ibid., p. 136.

12. Ibid., p. 148.

13. Michel FoucAuLt, Surveiller et punir. Naissance de la prison, op. cit.

14. Carlos LISCANo, Memorias de la guerra reciente, op. cit., p. 15-16.

15. Carlos LISCNAO, El furgón de los locos, op. cit., p. 69-70.

16. Carlos liscano, Memorias de la guerra reciente, op. cit., p. 37.

17. Carlos LISCANO, El furgón de los locos, op. cit., p. 18. Señalamos la existencia de una propaganda tupamara a propósito de las fugas, excepcionales por el número de presos y presas liberados, en MOVIMIENTO DE LIBERACIÓN NACIONAL, Tres evasiones de Tupamaros: operaciones Estrella, Abuso, Gallo.

18. Carlos LISCANO, Memorias de la guerra reciente, op cit., p. 39-40.

19. REAL ACADEMIA ESPAÑola, Diccionario de la lengua española, "fondear" [on-line], España, RAE [disponible el 13/03/2021].

20. Carlos LisCano, El furgón de los locos, op. cit., p. 27.

21. Ibid., p. 109.

22. Carlos Liscano, El furgón de los locos, op. cit., p. 36.

23. Carlos LISCANo, Memorias de la guerra reciente, op. cit., p. 97.

24. Erving GOFFMAN, Asiles. Études sur la condition sociale des malades mentaux, op. cit., p. 55-56.

25. Carlos LISCANo, El furgón de los locos, op. cit., p. 45-46

26. Ibid., p. 94.

27. Carlos LISCANo, Memorias de la guerra reciente, op. cit., p. 124-125.

28. Carlos LisCano, El furgón de los locos, op. cit., p. 83.

29. Ibid., p. 171.

30. Carlos LISCANO, Memorias de la guerra reciente, op. cit., p. 112.

31. Siempre descrita con esta palabra y con la mayúscula inicial.

32. Carlos LISCANO, Memorias de la guerra reciente, op. cit., p. 100.

33. Michael POLLAK y Nathalie HEINICH, «Le témoignage», Actes de la recherche en sciences sociales, $\mathrm{n}^{\circ}$ 62/63 (juin 1986), p. 3-29. 


\section{RESÚMENES}

Cet article a pour but d'interroger la représentation de la réclusion de l'auteur uruguayen Carlos Liscano dans deux de ses textes: Memorias de la guerra reciente, fiction publiée pour la première fois en 1988, et El furgón de los locos, témoignage des treize années qu'il a passées au pénitencier appelé «Penal de Libertad». Nous cherchons à montrer que ces deux textes sont deux étapes d'un long chemin vers la liberté totale, entravée par les effets de l'asilisation qu'a subie le prisonnier depuis son entrée dans l'institution totalitaire et encore de nombreuses années après sa libération effective. De plus, nous nous basons sur la manifestation des frontières de deux institutions totalitaires (le camp militaire et la prison) que représente l'auteur. Frontières qui semblent inscrire le reclus dans une situation hermétique que nous nous proposons de questionner.

The aim of this article is to interrogate the representation of the reclusion of Carlos Liscano in two texts of this Uruguayan author: Memorias de la guerra reciente, fiction published for the first time in 1988, and El furgón de los locos, testimony about the thirteen years he pasted in the penitentiary called «Penal de Libertad». I intend to show how those two texts present two steps of a long way to the complete liberty, complicated by the effects of asilization that the prisoner suffered since his integration in the total institution and still several years after his effective liberation. Moreover, I rely my research on the expression of the borders of the two total institutions (the military camp and the prison) which represent the author. Borders which seem to fall within the inmate in a hermetical situation whose I purpose to question.

\section{ÍNDICE}

Keywords: asilization, Carlos Liscano, reclusion, dictatorship, literature, testimony

Mots-clés: asilisation, réclusion, Carlos Liscano, dictature, littérature, témoignage

\section{AUTOR}

\section{ÉMILIE LEROUX}

Université de Perpignan-Via Domitia 